\title{
Appendix
}

\section{Continuous separation of isomers in fluidized bed crystallizers}

D. Binev, A. Seidel-Morgenstern, H. Lorenz

Description of the sub-models for growth, product removal and seed generation in the population balance (eq. 2)

Considering growth of the particles, the growth rate $\mathrm{G}$ required in eq. 2 can be considered in a simplified manner as linearly dependent on the local liquid phase concentration and the compound specific equilibrium concentration, $\mathrm{c}^{*}$, corresponding to the temperature in the crystallizer, $\mathrm{T}_{\text {cryst }}$ :

$$
\mathrm{G}(\mathrm{x}, \mathrm{t})=\mathrm{k}\left(\mathrm{c}(\mathrm{x}, \mathrm{t})-\mathrm{c}^{*}\left(\mathrm{~T}_{\text {cryst }}\right)\right)
$$

To quantify in the population balance the particle flux due to product removal at position $\mathrm{x}_{\mathrm{p}}, \dot{\mathrm{n}}_{\mathrm{p}}$, it is possible to specify the total volumetric solid phase flowrate, $\dot{\mathrm{V}}_{\mathrm{p} \text {,solid }}$, exploiting the local void fraction:

$$
\dot{\mathrm{V}}_{\mathrm{p}, \text { solid }}(\mathrm{t})=\left(\frac{\varepsilon\left(\mathrm{x}_{\mathrm{p}}, \mathrm{t}\right)}{1-\varepsilon\left(\mathrm{x}_{\mathrm{p},} \mathrm{t}\right)}\right) \dot{\mathrm{V}}_{\mathrm{p}, \text { liq }}(\mathrm{t})
$$

Furthermore, the mean local product particle size, $\bar{L}\left(x_{p}, t\right)$ can be calculated from eq. 4 , which allows determining the corresponding local particle number flux, $\dot{\mathrm{N}}_{\mathrm{p}}\left(\mathrm{x}_{\mathrm{p}}, \mathrm{t}\right)$, which matches the local volumetric solid phase flowrate:

$$
\dot{\mathrm{N}}_{\mathrm{p}}(\mathrm{t})=\frac{\dot{\mathrm{V}}_{\mathrm{p}, \text { solid }}(\mathrm{t})}{(\pi / 6) \overline{\mathrm{L}}^{3}(\mathrm{t})}
$$

This provides the size dependent product removal term for eq. 2 :

$$
\dot{\mathrm{n}}_{\mathrm{p}}\left(\mathrm{L}, \mathrm{x}_{\mathrm{p}}, \mathrm{t}\right)=\frac{\mathrm{n}\left(\mathrm{L}, \mathrm{x}_{\mathrm{p}}, \mathrm{t}\right)}{\mathrm{N}\left(\mathrm{L}, \mathrm{x}_{\mathrm{p}}, \mathrm{t}\right)} \dot{\mathrm{N}}_{\mathrm{p}}\left(\mathrm{x}_{\mathrm{p}}, \mathrm{t}\right)
$$

For all $\mathrm{x} \neq \mathrm{x}_{\mathrm{p}}$, the term $\dot{\mathrm{n}}_{\mathrm{p}}$ is zero. 
The last important feature of the process investigated is the crystal comminution due to ultra-sonication of a suspension withdrawn at $\mathrm{x}=0$ and realized in an external US-bath. It is assumed that all crystals taken from the bottom of the crystallizer are comminuted into a larger number of smaller crystals (seeds). For this seed generation, it can be assumed that no particle growth or dissolution take place in the bath.

As for the product removal at position $\mathrm{x}=0$, the suspension flowrate towards the US-bath is the decisive parameter, which specifies the US-bath residence time, $\tau_{\mathrm{us}}$. Thus, in analogy to eq. A-4 holds:

$$
\dot{\mathrm{n}}_{\rightarrow \mathrm{us}}(\mathrm{L}, \mathrm{x}=0, \mathrm{t})=\frac{\mathrm{n}(\mathrm{L}, \mathrm{x}=0, \mathrm{t})}{\mathrm{N}(\mathrm{L}, \mathrm{x}=0, \mathrm{t})} \dot{\mathrm{N}}_{\rightarrow \mathrm{us}}(\mathrm{x}=0, \mathrm{t})
$$

with

$$
\begin{gathered}
\dot{\mathrm{N}}_{\mathrm{us} \rightarrow}(\mathrm{x}=0, \mathrm{t})=\frac{\dot{\mathrm{V}}_{\mathrm{us}, \text { solid }}(\mathrm{t})}{\frac{\pi}{6} \overline{\mathrm{L}}_{\rightarrow \mathrm{us}}^{3}(\mathrm{x}=0, \mathrm{t})} \\
\dot{\mathrm{V}}_{\mathrm{us}, \text { solid }}(\mathrm{t})=\left(\frac{\varepsilon(\mathrm{x}=0, \mathrm{t})}{1-\varepsilon(\mathrm{x}=0, \mathrm{t})}\right) \dot{\mathrm{V}}_{\mathrm{us}, \mathrm{liq}}(\mathrm{t})
\end{gathered}
$$

The mean size of the crystals entering the US-bath, $\overline{\mathrm{L}}_{\rightarrow \mathrm{us}}$, can be derived from eq. 4 for position $\mathrm{x}=0$.

The distribution function characterizing the effluent of the US-bath can be described in a simplified manner assuming a generation of a Gaussian distribution with residence time dependent parameters:

$$
\mathrm{n}_{\mathrm{us} \rightarrow}(\mathrm{L}, \mathrm{x}=0)=\mathrm{N}_{\mathrm{us} \rightarrow} \exp \left(-\frac{\mathrm{L}-\overline{\mathrm{L}}_{\rightarrow \mathrm{us}}\left(\tau_{\mathrm{us}}\right)}{\sigma^{2}\left(\tau_{\mathrm{us}}\right)}\right)^{2}
$$

Hereby, the residence time, $\tau_{\mathrm{us}}$ corresponds to the ratio of US-bath volume over the suspension flowrate through the bath.

In order to conserve the solid phase mass balance in the US-bath, assuming steady state, it should hold: 


$$
\frac{\mathrm{N}_{\mathrm{us} \rightarrow}}{\mathrm{N}_{\rightarrow \mathrm{us}}}=\frac{\dot{\mathrm{N}}_{\mathrm{us} \rightarrow}}{\dot{\mathrm{N}}_{\rightarrow \mathrm{us}}}=\frac{\overline{\mathrm{L}}_{\mathrm{us} \rightarrow}}{\overline{\mathrm{L}}_{\rightarrow \mathrm{us}}}
$$

This provides $\dot{\mathrm{n}}_{\mathrm{us} \rightarrow}$ using eq. A-5 with the corresponding quantities given above. 